\title{
Tributo y mita urbana. Movilización y migración indígena hacia Quito en el siglo XVII*
}

\author{
Tribute and Urban Mita. Mobilization and Indigenous \\ Migration to Quito in the Seventeenth Century
}

\author{
Carlos D. Ciriza-Mendívil \\ ORCID iD: https://orcid.org/0000-0002-2193-5978 \\ Universidad Pública de Navarra
}

\begin{abstract}
El amplio número de naturales que habitaban la ciudad de Quito para mediados del siglo XVII plantea numerosas cuestiones. A fin de cuentas, al tratarse de una urbe de origen colonial esta población de indígenas migrantes había acudido a la capital de la Audiencia por varios motivos. El objetivo de este estudio es, por un lado, mostrar la extensión de la tributación indígena y del servicio de la mita en la ciudad de Quito, cuya evasión ha sido punto central en numerosos análisis de movilidad indígena. Y por otro, presentar la conjunción de diversos factores que hicieron del núcleo urbano quiteño un foco de atracción poblacional indígena masivo desde mediados del siglo XVI hasta finales del siglo XVII.

Palabras Clave: Quito; Siglo XVII; Indígena; Migración; Ciudad; Tributo; Mita.

By the seventeenth century most of the population of the city of Quito were natives. Being a colonial city this abundance and the magnitude of the indigenous migration to the urban sphere pose many questions. In one side, this article has the objective to show the extend of tributes in the city of Quito between natives and the importance of mita service at the urban sphere. On the other side, this study will present the conjunction of elements that made the city of Quito such an important place of attraction to indigenous population since sixteenth century to the end of the seventeenth century.
\end{abstract}

KeYwords: Quito; Seventeenth Century; Indigenous; Migration; City; Tribute; Mita.

Copyright: @ 2019 CSIC. Este es un artículo de acceso abierto distribuido bajo los términos de la licencia de uso y distribución Creative Commons Reconocimiento 4.0 Internacional (CC BY 4.0)

* Este trabajo ha sido realizado gracias a la financiación de la Fundación de Promoción de la Investigación José Luis de Oriol-Catalina de Urquijo. 


\section{Introducción}

El entendimiento de la Monarquía Hispánica como una administración cuya expansión se basó, principalmente, en la implantación y constitución de urbes a lo largo de todo el territorio americano es un planteamiento ya tradicional. Sin embargo, el análisis de los naturales que habitaron estas ciudades no lo ha sido tanto. La división - en cierta manera utópica- de la sociedad hispana en dos repúblicas, una de «naturales» y otra de «españoles», conllevaba también una supuesta separación geográfica de ambas poblaciones. Así, si «yndios» y españoles no podían cohabitar los mismos espacios y las ciudades habían sido fundadas como «esferas hispanas», los naturales iban a encontrarse principalmente en el espacio rural.

Durante un tiempo, estos posicionamientos se trasladaron a la historiografía. Así, como señalara Felipe Castro para el caso de la Nueva España ${ }^{1}$ el conocimiento de las pequeñas poblaciones indígenas rurales en la Audiencia de Quito era en ocasiones mayor que el que se tenía de las grandes masas de naturales urbanos. ${ }^{2}$ En todo caso, lo cierto es que desde las décadas de los 70 y 80 del pasado siglo comenzaron a proliferar aquellos análisis que, de forma incipiente, a veces de manera más bien indirecta, ${ }^{3}$ observaron la abundancia de estas poblaciones indígenas y su importancia en los devenires sociales, económicos y políticos de las ciudades de la América hispana.

Excepcionales ejemplos por su especial atención a dichas poblaciones del espacio andino serían, entre muchos otros, los estudios de Sánchez Albornoz sobre la ciudad de Arequipa, los de Gisbert para las urbes de la Audiencia de Charcas, los trabajos de Lowry y de Paul J. Charney para la capital virreinal y la obra de Salomon para el caso quiteño. ${ }^{4}$

En definitiva, amplios estudios que sentaron las bases ${ }^{5}$ de los nuevos acercamientos a los análisis de indígenas urbanos que, desde principios de la

1 «Sabemos más acerca del tributo y formas de gobierno de pequeñas poblaciones como Tlapa o Jilotepec que sobre los miles de habitantes nativos de Puebla, Guanajuato o Mérida», Castro Gutiérrez, 2010b, 11.

2 Para el caso ecuatoriano, existen ejemplos evidentes como los de las comunidades de Cumbayá, Otavalo o Lumbisí sobre los que se han hecho numerosos estudios. Moreno Yánez, 1981a; 1981b. Rebolledo González, 1992. Espinoza Soriano, 1999.

3 Los ejemplos son múltiples, véanse especialmente, Assadourian, 1983; Charney, 1988; Zulawski, 1987.

4 Sánchez Albornoz, 1982; 1988; 2003. Charney, 1996; 2012. Salomon, 2011.

5 Para una visión más amplia de esta historiografía en el espacio andino véase PoloniSimard, 2000. 
década de los 2000 —influenciados por el retorno al sujeto en la historiografía-,${ }^{6}$ han ido extendiéndose a gran parte de las urbes latinoamericanas. ${ }^{7}$ Sea como fuere, los campos sobre los que profundizar en torno a los indígenas urbanos son todavía múltiples. Al fin y al cabo, en casos como el de la ciudad de Quito, solo se ha arañado la superficie de poblaciones cuyas complejas dinámicas y prácticas sociales más cotidianas se implantaron en el espacio americano de interacción y coexistencia étnica por antonomasia: la ciudad.

\section{Del origen de la ciudad al origen de la población}

El origen de los elementos constitutivos de un análisis —en este caso la ciudad de Quito y sus indígenas - no determina su evolución posterior, pero está claro que la influye. Así, ha sido en cierta manera habitual, entre los estudios de indígenas de la urbe, plantearse el origen de la misma. ${ }^{8} \mathrm{De}$ esta manera, si se trataba de una ciudad de origen prehispánico, la lógica continuista explicaba en gran medida la existencia de amplias masas de naturales dentro de la traza y en sus contornos. Ejemplos paradigmáticos serían la Ciudad de México, Cuzco o, para la Audiencia de Quito, la ciudad de Cuenca (antigua Tomebamba). Por el contrario, si el análisis se centraba en una urbe de origen hispano, era comprensible que el número de naturales fuese más reducido y se instalase en los contornos de la traza. ${ }^{9}$

Para el caso de Quito la realidad fue un poco diferente. Más allá de la existencia o no de edificios incaicos, de lugares de culto o de enclaves defensivos del Tawantinsuyu, ${ }^{10}$ cuyos registros han sido defendidos por unos

6 Ponce Leiva y Amadori, 2008, 18.

7 Véase para Nueva España, Castro Gutiérrez (2010a); para Santa Fe de Bogotá, Zambrano Escovar (2008) y Gómez Gómez (2015); para la Capitanía General de Santiago de Chile, Valenzuela (2014) y Contreras (2010); para la Audiencia de Charcas, Escobari de Querejazu (2005) y Gil Montero (2013; 2015); para la Audiencia de Lima, Argouse (2008) y Ramos (2010; 2012); y para la Audiencia de Quito, Poloni-Simard (2000; 2006) y Ciriza-Mendívil (2017a; 2017b).

8 Castro Gutiérrez, 2010b, 11-14.

9 Véase a este respecto el caso de Puebla de los Ángeles estudiado por Gómez García, 2010.

10 Los que defienden la existencia de una ciudad quiteña prehispánica se basan principalmente en tres informaciones: la descripción de Pedro Cieza de León, señalando que la ciudad de Quito «está asentada en unos antiguos aposentos que los Ingas habían en el tiempo de su señorio mandado hacer en aquella parte, y habialos ilustrado y acrecentado Guaynacapa y el gran Topainga»; la división del Incario en dos mitades a las que se hace referencia, entre otras, en la Relación de los Quipucamayos redactada por Vaca de Castro (Larraín Barros, 1980, 88, 234-236); y las alusiones a diferentes edificios existentes que se hacen en las actas del cabildo quiteño desde los primeros años. Sin embargo, ninguno de estos tres elementos hace referencia explícita a la existencia de una ciudad, hecho corroborado por los escasos hallazgos arqueológicos. Jara Chávez, 2008, 88. 
y rebatidos por otros, no se puede hablar de una población urbana ${ }^{11}$ ni de una sociedad citadina plenamente constituida antes de la llegada de los españoles. ${ }^{12}$ En todo caso, la Hoya de Quito, con una localización estratégica entre los cacicazgos del norte andino, ${ }^{13}$ se conformó como un lugar de intercambio inter-regional sumamente importante con base en un mercado central. ${ }^{14}$ Un valle bastante poblado, con centros de población relativamente concentrada como Cotocollao o Guayllabamba, cuya importancia fue fundamental en los últimos momentos de expansión inca hacia el norte, ${ }^{15}$ pero que en ningún caso se constituyó como una ciudad a la manera de Cuzco o Tomebamba.

Así pues, el argumento de la lógica continuista para explicar la presencia de población indígena presentaba numerosas dificultades para su aplicación en el caso quiteño. Bien procedentes de lugares alejados, bien originarios de poblaciones al interior de la Hoya de Quito, los indígenas urbanos de esta ciudad creada ex novo fueron inevitablemente de origen migrante. En todo caso, este origen no implica un número poblacional reducido para la capital de la Audiencia. Pese a las innumerables problemáticas que presentan los estudios demográficos para épocas pre-estadísticas como el siglo XVII, la mayoría de los historiadores han señalado un tamaño considerable para la ciudad de Quito en esta época.

Según las estimaciones más elevadas, a mediados del XVII la capital de la Audiencia contaba con alrededor de cuarenta o cincuenta mil habitantes. ${ }^{16}$ Para los estudiosos más moderados, la población alcanzaba, como mínimo, unos veinticinco o treinta mil residentes; de todos ellos «hasta 3.500 vecinos y moradores dentro de la ciudad y sus 5 leguas, sin los indios

11 Salomon, 2011, 151. Si bien en otra de sus obras el mismo autor señalaba que Quito pudo haber sido una corte incaica, nunca hacía referencia a un ámbito urbano (Salomon, 1976, 151).

12 La definición de urbe se torna un elemento sumamente complejo merecedor de análisis más profundos. Por el momento, este estudio se limitará a seguir la conocida definición de Sebastián de Covarrubias, para quien una ciudad era «multitud de hombres ciudadanos, que se ha congregado a vivir en un mesmo lugar, debaxo de unas leyes y un gobierno» (Tesoro de la lengua castellana, o española, Madrid, 1611, 194v.).

13 Moreno Yánez, 1981a, 148.

14 Ramón Valarezo, 1992, 52-53.

15 Más aún, muchos de estos núcleos como Amaguaña, Sangolquí, Alangasí, Conocoto, Machachi, Pomasqui, El Quinche, Puembo, Pongolqui, Urin chillo, Anan Chillo, Uyumbicho, entre otros, seguirán existiendo durante todo el siglo XVII. Salomon, 2011, 113-115. Landázuri, 1990, 54.

16 Como en la mayoría de ciudades de la América hispana, para el siglo XVII existe una gran variación cuando se trata de cuantificar la población. Esta cambia según la documentación que se utilice, los multiplicadores para la conversión de tributarios en número de individuos, etc., de ahí los diferentes datos poblacionales. Phelan, 1996, 92. Powers, 1994, 329. Minchom, 2007, 277. 
que asisten en ella; criollos y traginadores, mujeres, niños y de todos sexos, 25.000 personas». ${ }^{17}$ Incluso para los coetáneos, el crecimiento de la población indígena en toda la sierra de la Audiencia de Quito durante el siglo XVI y XVII constituía una sorpresa. ${ }^{18}$ Así, en 1627 , el presidente de la Audiencia informaba en un memorial que en el caso quiteño «los naturales no sean disminuido antes ban en crecimiento». ${ }^{19}$

La historiografía, que en un momento inicial entendió este fenómeno como un crecimiento vegetativo sostenido gracias a condiciones climatológicas y productivas más ventajosas que en otros lugares, ${ }^{20}$ pronto encontró otros argumentos. Así, los análisis de movilidad indígena llevados a cabo por Powers observaron cómo la curva demográfica ascendente no era consecuencia de un crecimiento natural, «sino más bien de las migraciones de indígenas durante el siglo XVII desde las áreas marginales hacia el centro de la Audiencia». ${ }^{21}$ Esto es, una migración que desde las «tierras calientes» al este y al oeste de la sierra quiteña se dirigía hacia esta última, principalmente a sus centros urbanos como Latacunga, Cuenca, Ambato, Riobamba $\mathrm{y}$, especialmente, Quito.

Todas las ciudades del Antiguo Régimen fueron deficitarias de población por su gran mortandad. ${ }^{22}$ Las duras condiciones laborales, las enfermedades, los terremotos y las sequías configuraron unas urbes ${ }^{23}$ en las que cualquier aumento, incluso el simple mantenimiento del tamaño poblacional, se sostuvo gracias a la migración y Quito no fue una excepción. ${ }^{24}$ Únicamente cuando los flujos poblacionales cambiaron de objetivos

17 Descripción de Diego Rodríguez Docampo (1650), en Ponce Leiva, 1992, 212.

18 Si bien en la actualidad autores como Saignes (1985) han relativizado en cierta medida la pérdida poblacional peruana del siglo XVII, los informes coetáneos informaban de un descenso de naturales importante.

19 Relación del estado eclesiástico y civil de Quito por el presidente Antonio Morga (1627), en Burgos Guevara, 1995, 142-143.

20 Tyrer $(1988,46)$, quizás exageradamente, calcula un crecimiento de la población de la Audiencia de Quito entre 1591 y 1660 de alrededor de un $60 \%$ al pasar de 144.000 a 230.000 indígenas.

21 Powers, 1994, 384.

22 Minchom, 2007, 40. Ramos, 2010, 171.

23 Valenzuela, 2014, 18.

24 Suzanne Alchon lleva a cabo una enumeración de las continuas enfermedades que, entre la gran epidemia de 1648 y las que sacudieron la última década del siglo XVII, afectaron a la ciudad de Quito de forma recurrente. Asimismo, señala los problemas relativos al clima y al abastecimiento de comida que sucedieron durante todo el siglo XVII, pero principalmente a medidos de la centuria. Únicamente cuando se trataba de grandes epidemias la mortandad en el campo podía igualar e incluso superar a la de la ciudad, aunque esto no era lo habitual dados los menores niveles de densidad poblacional del ámbito rural. Alchon, 1991, 58 y 61-65. 
y destinos, ${ }^{25}$ la capital de la Audiencia y, en general, las urbes de la sierra sufrieron una disminución poblacional, pero esto no ocurrió hasta el siglo XVIII. Se trató, pues, de una migración indígena masiva y constante, que durante casi siglo y medio hizo de la ciudad de Quito la más poblada de toda la Audiencia y uno de los grandes centros urbanos del virreinato.

\section{La ciudad y el tributo}

Las causas de este vasto fenómeno migratorio se convirtieron, simultáneamente, en factores capitales al interior de la sociedad indígena quiteña del siglo XVII y elementos claves en los devenires socio-económicos de la administración hispana en la propia Audiencia. Dejando de lado visiones hasta cierto punto idílicas como principales motores de migración, gran parte de los análisis migratorios han observado el factor económico como uno de los estímulos fundamentales de la movilidad indígena. ${ }^{26}$

Únicamente poblaciones específicas de naturales y determinados individuos, como los caciques, consiguieron estar legalmente exentos del pago de tributo. El resto de indígenas del común entre 18 y 50 años, salvo algunas excepciones, ${ }^{27}$ hubieron de afrontar ese gasto. Este hecho ha convertido la evasión o reducción tributaria — junto con la huida del trabajo mitayoen uno de los elementos fundamentales para los análisis de movilidad indígena, tanto en la Audiencia de Quito como en otros espacios. ${ }^{28} \mathrm{Al}$ fin y al cabo, la administración hispana configuró un tributo partiendo de una población que debía permanecer estática, por lo que la migración de un espacio a otro podía conllevar la «desaparición» formal de estos indígenas de los registros tributarios.

Sin embargo, aplicar esta hipótesis al caso de la migración hacia la ciudad de Quito presenta varios problemas. El primero, que los movimientos poblacionales de indígenas fueron generalizados pero no se dirigieron exclusivamente a Quito. Con el objetivo de escapar de la explotación

25 Minchom, 2007, 17-18.

26 Entre otros, Jalpa Flores, 2010, 82; Powers, 1994; Sánchez Albornoz, 1982.

27 Recogidas en la Recopilación de Leyes de Indias (1681), lib. VI, tít. V, leyes XVIII, XIX y XX.

28 Minchom, 2007, 67-68. Barrios Escobar, 1996, 95. Escobari de Querejazu, 2005, 227-228 Incluso, algunos lo han relacionado con la conversión de indígenas a yanaconas en las urbes durante el siglo XVII. Glave, 1987, 48. 
española los naturales se movilizaban, ${ }^{29}$ pero el destino de esta migración podía ser la urbe u otras comunidades rurales. ${ }^{30} \mathrm{~A}$ fin de cuentas, la exoneración de la mita y la variación o evasión del tributo, causas principales de esta migración según algunos historiadores, ${ }^{31}$ afectaban a los forasteros indistintamente en el espacio rural y urbano. De esta manera, si el objetivo fue evadir la mita y variar o evitar el pago del tributo, los indígenas encontraron un escenario potencialmente similar en la ciudad de Quito y en el campo.

El segundo problema — quizás el fundamental—, que la urbe quiteña no se convirtió en absoluto en un espacio de evasión fiscal per se. Más aún, ni siquiera otorgó un pago excepcionalmente reducido a los indígenas que habitaron la misma..$^{32}$ Así, yanaconas, mitimaes, naturales forasteros y vagabundos debieron hacer frente a la carga económica que supuso el tributo. ${ }^{33}$ Todo dependía de la capacidad de la administración hispana para hacerse presente y de la habilidad de los caciques para recaudar el tributo o para ocultar a sus naturales.

En teoría, el pago se fijaba de acuerdo a la fertilidad de las tierras y las condiciones de la comunidad ${ }^{34}$ y no en función de si el indígena era natural o forastero, rural o urbano. Así, para el caso de la ciudad de Quito y sus poblaciones aledañas la tasa de tributo fluctuaba relativamente poco: entre dos pesos y medio más un ave - equivalente a un real- y dos pesos y media ave por tercio. Pagados, como en el espacio rural, en los tercios de Navidad y de San Juan, ${ }^{35}$ estos cobros tributarios se desarrollaron en todas las parroquias de la ciudad de Quito, evidenciando tanto la posibilidad de la

29 Powers, 1994, 8.

30 La hipótesis central de Powers es que los caciques utilizaron a estos forasteros durante el siglo XVII para contar con una mano de obra libre de tributación, aprovechando que «los forasteros se encontraban exentos de la mita y del tributo, para un cacique era preferible tener un contingente de forasteros viviendo en su comunidad que tener una población homogénea de originarios en la cual todos estaban sujetos al sistema laboral español»; en sus palabras, una especie de «sillas musicales» en las que los indígenas pasaban de una comunidad de indígenas a otra. Ibidem, 84 y 220.

31 Bonnett, 1992, 94.

32 Situación similar se detectaba, por ejemplo, para el caso novohispano de Valladolid de Michoacán, donde según Paredes Martínez (2010, 39), los indígenas de la urbe llegaron a ser definidos en gran medida por el tributo que pagaban y los servicios laborales que prestaban.

33 Recopilación de Leyes de Indias, lib. VI, tít. V, leyes III, V y VI.

34 Ayala Mora, 1983, 152.

35 Si bien la Recopilación de Leyes de Indias (lib. VIII, tit. IX, ley III) especificaba que los tributos se «vayan cobrando por los tercios del año de cuatro en cuatro meses», las cartas cuentas muestran que el cobro se efectuaba cada seis meses, en San Juan (junio) y en Navidad (diciembre), lo que paradójicamente hizo a los tercios semestrales y no cuatrimestrales, probablemente con el objetivo de simplificar el cobro del tributo. 
administración de cobrar estos tributos como la cohabitación de indígenas —naturales y vagamundos- en todos los espacios urbanos.

Aunque no es habitual contar con tablas comparativas y seriadas de estos pagos a lo largo de amplios periodos, en determinados momentos - 1669, 1670 y 1682 a 1686 - las cartas cuentas ${ }^{36}$ ofrecieron una visión relativamente amplia de toda la urbe e incluso de parte del corregimiento. Así, por ejemplo, el tercio de Navidad de 1669 evidenciaba que la contribución de los indígenas de la ciudad, tanto de vagamundos como de naturales, había sido muy similar. De esta manera, por señalar algunos ejemplos, los naturales de las parroquias de San Blas y Santa Prisca de la Real Corona, a cargo de don Cristóbal Cachuquina, estaban tasados en dos pesos y medio por tercio, ${ }^{37}$ lo mismo que los indígenas vagabundos de la parroquia de Santa Bárbara, a cargo de don Blas Cañar ${ }^{38}$ los de la parroquia de San Roque, a cargo de don Torivio Acuas, ${ }^{39}$ y los de Santa Prisca, a cargo de don Miguel Ypucurru. ${ }^{40}$

$\mathrm{Al}$ ampliar el marco temporal y geográfico, las realidades observadas eran similares. Más aún, por un lado se evidenciaba la existencia de un amplio número de indígenas tributarios en la ciudad (ascendiendo en periodos a más de 1.600$)^{41}$ y por otro, se observaba la escasa variación en la tasa tributaria de las distintas comunidades. Para el periodo de 1686 a 1689 las cartas cuentas presentadas por el corregidor don Luis Altamirano mostraban otro elemento característico más, la nula modificación tributaria a lo largo del tiempo. Así, dentro de la traza urbana, por señalar varios ejemplos, los indios vagabundos de la parroquia de San Roque estuvieron tasados en dos

36 Con el nombre de cartas cuentas se conocía en la Audiencia de Quito a la documentación elaborada por el corregidor y que recogía los ingresos y gastos descontados de los tributos a los indígenas. Por lo tanto, no se trataba del resumen de todas las operaciones de cobro o pago efectuadas por una Caja Real durante un período fiscal — tan pormenorizadamente analizadas en la monumental obra de Herbert Klein y John TePaske (1982)—, sino del ramo de tributos, es decir, el resumen que de sus cuentas en torno a los tributos indígenas entregaba el corregidor de la ciudad de Quito a los oficiales de la Real Hacienda en esta Audiencia.

37 Carta cuenta de los tributos de 1669 de los indios de la parroquia de San Blas de esta ciudad de la Real Corona, Quito, 1670, Archivo Nacional del Ecuador (ANE), Fondo Corte Suprema, Sección Tributos, caja 3, exp. 20.

38 Carta cuenta de los tributos de 1669 de los indios vagamundos de la parroquia de Santa Bárbara, Quito, 1670, ANE, Corte Suprema, Tributos, caja 4, exp. 2.

39 Carta cuenta de los tributos de 1669 de los indios vagamundos de San Roque, Quito, 1670, ANE, Corte Suprema, Tributos, caja 4, exp. 8.

40 Carta cuenta de los tributos de 1669 de los indios de la parroquia de Santa Prisca, Quito, 1670, ANE, Corte Suprema, Tributos, caja 4, exp. 3.

41 Testamento de doña Francisca del Espinal, Quito, 23-X-1660, ANE, Protocolos, Notaría 1a, vol. 199 , f. $340 \mathrm{r}-341 \mathrm{v}$. 
$\operatorname{pesos}^{42}$ y un ave por tercio; los vagabundos de San Marcos y los de la parroquia de San Sebastián, en dos patacones y media ave, y los vagabundos de la parroquia de San Marcos, pertenecientes a la encomienda del capitán don Juan de Villandrande, en dos patacones y un ave por tercio; ${ }^{43}$ y pagaron estas cantidades a lo largo de todo el siglo.

Incluso más allá de la traza urbana, en el espacio rural circundante a la ciudad de Quito, esto es, en sus «cinco leguas», los tributos fueron similares. Así, los indígenas naturales del pueblo de Conocoto, los del pueblo de Santa María Magdalena, los de Guangopolo y los naturales y forasteros del pueblo de Sangolquí pagaban por cada tercio dos patacones y media ave. ${ }^{44}$ Los indígenas vagabundos del partido de Anansayas y los vagabundos del pueblo de San Juan Evangelista a cargo de don Andrés Cajamarca estaban tasados en dos pesos y un ave; mientras que los indígenas vagabundos del pueblo de Santa María Magdalena a cargo de don Luis Tituaña y los del pueblo de Pansacoto a cargo de don Gabriel Achig debían pagar doce reales y un ave por tercio. ${ }^{45}$

Si bien en algunos casos los indígenas hubieron de afrontar el pago de cantidades más bajas de lo habitual — como los «yndios» de la parroquia de Santa Prisca a cargo de don Miguel Ypucuru, que tributaban veinte reales y un ave-,${ }^{46}$ lo cierto es que estas diferencias fueron mínimas. Además, no estuvieron directamente relacionadas con la condición de los indígenas como naturales o forasteros, ni siquiera con su residencia en la urbe o en el espacio rural. Más bien parecen haber sido influenciadas por las condiciones específicas en las que se desarrolló la numeración y la carta cuenta de cada comunidad. En definitiva, como señalara Montero para otros espacios ${ }^{47}$ gran parte de los naturales y un número importante de forasteros

42 Las referencias monetarias más habituales entre los indígenas y gentes del común de la ciudad de Quito para el siglo XVII fueron pesos de a ocho reales y patacones, ambas de igual valor. Sus equivalencias, si bien con discrepancias, se establecen en aproximadamente 450 maravedís por cada uno de ellos. Aunque hubo diversos valores para reales y pesos (Escobari de Querejazu, 2005, 223-224) para el caso quiteño el más común era el peso de 8 reales, también denominado real de a ocho.

43 Cartas cuentas de los indios de Quito y sus cinco leguas, Quito, 1690, ANE, Corte Suprema, Tributos, caja 5, exp. 12, f. 2v-3r, 4r, 17r y 44r-44v.

44 Cartas cuentas que hacen los jueces o fiscales de la Real Hacienda de Quito y sus provincias de los tributos de esta ciudad, Quito, 1669, ANE, Corte Suprema, Tributos, caja 4, exp. 15, f. 5v, 6v, $9 \mathrm{v}$ y $15 \mathrm{v}$.

45 Cartas cuentas de los indios de Quito y sus cinco leguas, Quito, 1690, ANE, Corte Suprema, Tributos, caja 5, exp. 12, f. 3r-3v, 9r.

46 Carta cuenta de los tributos de 1669 de los indios de la parroquia de Santa Prisca, Quito, 11 de febrero de 1670. ANE, Corte Suprema, Tributos, caja 4 (1670-1685), exp. 3.

47 Un forasterismo tributario en su mayoría ya ha sido mencionado para regiones de Bolivia por Gil Montero $(2013,45)$. 
estaban tributando en la ciudad de Quito en el siglo XVII, ${ }^{48}$ poniendo en cuestión la hipótesis de una evasión e incluso de un intento de reducción fiscal como motor principal de movilidad indígena hacia la capital de la audiencia.

Solo el completo anonimato de los barrios citadinos, esgrimido por algunos autores como posible móvil migratorio ${ }^{49}$ pudo permitir a los naturales evadir el tributo en la ciudad. Sin embargo, varios elementos llevan a relativizar el ocultamiento de estos «yndios» en el espacio urbano. Por un lado, los naturales no buscaban desaparecer para la sociedad, sino simplemente hacerlo para la Real Hacienda, manteniendo en numerosos casos los vínculos sociales que les situaban en su contexto. ${ }^{50}$ Esta estrategia no era netamente urbana sino que, como evidenció Powers, pudo desarrollarse también en el espacio rural. ${ }^{51}$ Y por otro lado, la ciudad se convirtió en el espacio donde desde muy pronto la tributación de forasteros y «vagamundos» fue algo habitual. La preocupación por parte de la administración hispana de aplicar el tributo a los indígenas configuró, para el siglo XVII, un número amplio de cacicazgos y señores naturales implantados en la traza urbana cuyas parcialidades, de vagamundos y forasteros, tributaban con regularidad.

A fin de cuentas, como señalara Juan de Matienzo para el espacio peruano, los indígenas quiteños tampoco desaparecían realmente de los registros..$^{52}$ Más aún, es probable que en su intento de ocultamiento y

48 Si bien las problemáticas en torno a la población total de la ciudad nos impiden en el presente estudio llevar a cabo porcentajes tan exactos como los elaborados por Gil Montero (2013, 44), para los períodos de 1669, 1672-1675 y 1682-1686 el número total de tributarios dentro de la traza ascendía, al menos, a 1.314, 1.367 y 1.625 respectivamente, evidenciando tanto la amplitud de esta tributación como el aumento de la base poblacional de la misma a lo largo del tiempo. Cartas cuentas que hacen los jueces o fiscales de la Real Hacienda de Quito y sus provincias de los tributos de esta ciudad, Quito, 1669, ANE, Corte Suprema, Tributos, caja 4, exp. 15. Carta cuentas de los indios del corregimiento de Quito para los años de 1673 a 1675, Quito, 15 de mayo de 1680, ANE, Presidencia de Quito, caja 4 (1675-1680), vol. 10 (1678-1679). Carta cuenta de los indios de Quito y sus cinco leguas, Quito 1690, ANE, Corte Suprema, Tributos, caja 5 (1686-1699), exp. 12.

49 Moreno Yánez, 1981a, 207.

50 Los indígenas no rompían estos lazos que, además de situar, amparaban y protegían. Véase Ciriza-Mendívil, 2017a. En todo caso, en torno a esta cuestión ha habido importantes debates. Entre aquellos que defendían el desarraigo de estos migrantes véase Ares Queija, 1999, 136; Sánchez Albornoz, 1982, 273. Para aquellos que mostraban migraciones colectivas mucho más conectadas con sus lugares de origen y con multitud de individuos, véase, entre otros, Powers, 1994; Saignes, 1985.

51 Powers $(1994,69-70)$ muestra el interés de los caciques por ocultar a su propia población, lo que consecuentemente facilitaba esta huida.

52 Parece que Matienzo (1967 [1567], 96) tenía razones para despreocuparse por los indígenas huidos ya que, como correctamente señalaba, estos en ocasiones estaban en pueblos donde se ocupaban de sus oficios o habitaban en chacras donde no les faltaba doctrina y además se les podría cobrar tributo. 
evasión tributaria estos naturales fueran el verdadero centro de todas las miradas, tanto por parte de la administración hispana como de los caciques. ${ }^{53}$

\section{La mita ¿motor de huida o motor de atracción?}

Las cargas tributarias no han sido el único factor señalado como causante de movimientos de poblaciones indígenas. Según algunos estudios, al dirigirse a la urbe y abandonar sus comunidades, los «yndios» forasteros trataban de reducir o evadir su tributo, pero también de evitar en la medida de lo posible el servicio mitayo. ${ }^{54}$ Sin embargo, a pesar de su origen, ${ }^{55}$ este trabajo forzado por turnos ${ }^{56}$ nunca estuvo limitado a la actividad minera ni al espacio rural, sino que se extendió rápidamente a todo tipo de ámbitos y sectores económicos susceptibles de verse beneficiados por la participación de una mano de obra mitaya. ${ }^{57}$

La amplia lista de mitas no se aplicó de la misma manera en todos los territorios de la América hispana, por lo que bien pudiera ser este servicio laboral un elemento descriptor del contexto económico en el que se insertaba. Para la urbe quiteña fueron habituales durante todo el siglo XVII la mita de acequias y aguas, la de leña, la de servicios domésticos, la de correos, la de construcción y reparación de edificios ${ }^{58}$ y la de obras públicas, entre muchas otras. ${ }^{59} \mathrm{~A}$ pesar de que algunas de ellas fueron temporalmente abolidas en Quito e Ibarra a principios del siglo XVII, no parece que la disposición de la Audiencia hubiese tenido efectos en la práctica. Así, todavía en el siglo XVIII perduraban un gran número de estos trabajos forzados tanto en el espacio rural como en la ciudad de Quito. ${ }^{60}$

En teoría, la mita urbana o «mita de plaza» debía destinarse a obras de interés para la «república». Sin embargo, la gama de elementos que eran

53 Moreno Yánez, 1989, 249.

54 Powers, 1994, 8.

55 Para la época colonial, en las minas de Huamanga primero y, de forma oficial, a partir de 1573 para Potosí. Cole, 1985, 8-12.

56 Moreno Yánez, 1981a, 254.

57 Pérez Tamayo, 1987, 67.

58 Webster $(2012,12)$ muestra cómo desde principios de la colonia numerosos oficios de la construcción eran provistos a través de la mita.

59 Existe una multitud de mitas que se desarrollan en la ciudad de Quito, algunas de ellas aparecen mencionadas desde bien pronto y otras ya están constituidas para finales del XVI y reflejadas por la visita de Gaspar de San Martin y Juan Mosquera para el año 1599. Salomon, 1976.

60 Minchom, 2007, 52. 
beneficiosos para la «república» se amplió y modificó a lo largo del tiempo en la ciudad de Quito. Desde la reparación de puentes de la urbe ${ }^{61}$ a la construcción o restauración de las casas de algunos vecinos; ${ }^{62}$ la mita fue extendiéndose a multitud de ámbitos, perpetuándose ${ }^{63} \mathrm{y}$ ampliando la base de oficios que proveía. La ciudad no estuvo exenta siquiera de la mita minera, sumamente escasa en la Audiencia de Quito y prácticamente extinta a mediados del siglo XVII. ${ }^{64}$ Así, cuando a finales de la centuria anterior faltaron indígenas en las minas de Zaruma, toda la Audiencia —incluida la ciudad de Quito- hubo de contribuir con mano de obra mitaya. ${ }^{65}$ En todo caso, la obrajera fue la mita que empleó a un número mayor de indígenas en la urbe quiteña y sus contornos. Según Phelan más de 28.800 indígenas trabajaban en los obrajes de la Audiencia, ${ }^{66}$ cifra que para la ciudad de Quito era reducida por Tyrer a $10.000 .{ }^{67} \mathrm{Se}$ trataba de un sector cuyo crecimiento se había originado en el siglo XVI, pero que para el año 1604 contaba con «mas de sesenta obrajuelos [...] para sayales, xergas y freçadas y en ellos ocupan los indios». ${ }^{6}$

En definitiva, con el paso del tiempo la mita se había diversificado ${ }^{69}$ perpetuándose como una herramienta sumamente útil para la economía quiteña y, consecuentemente, para la administración hispana. De esta manera, más que huir de este trabajo forzado, los indígenas que se dirigieron hacia la ciudad de Quito lo hicieron hacia un espacio en el que este servicio estaba bastante extendido. Los «yndios» podían evitar las mitas menos comunes en la ciudad, pero se encontrarían cada cinco años sirviendo otras en el propio ámbito urbano. Al regular los trabajos de la mita, la legislación

61 «Se nombran diputados para que acudan con el teniente de las cinco leguas y el procurador general y saquen los indios de Cayambe, Taguacundo y Tocache para el reparo del puente de Pisque», 15 de mayo de 1668, en Actas del Cabildo Colonial de San Francisco de Quito de 1664 a 1669, versión de Judith Paredes Zarama, Quito, Archivo Municipal, 1995, 328-329.

62 «Trata el cabildo sobre reparaciones de las calles y puentes de la Ciudad-Mitayos», 4 de mayo de 1652, en Libro de Cabildos de la Ciudad de Quito. 1650-1657, versión de Gustavo Chiriboga, Quito, Archivo Municipal, 1969, 169-171.

63 Cook, 1989, 133.

64 Moreno Yánez, 1981a, 254.

65 Ortiz de la Tabla $(1993,9)$ expone cómo a fines del siglo XVI se sacaban excedentes de población de Quito para las minas de Zaruma y para obrajes de Riobamba. Lo mismo señala Pérez Tamayo (1987, 226).

66 Phelan, 1996, 120.

67 Tyrer, 1988, 91.

68 Memorial del fiscal licenciado don Blas de Torres Altamirano (1604), cit. en Burgos Guevara, 1995, 135.

69 Cook, 1989, 133. 
toledana ${ }^{70}$ aceleró un movimiento poblacional ya tradicional entre los indígenas y modificó sus destinos. ${ }^{71}$ Los considerables números que la mita obligaba a movilizar — un quinto de la población tributaria para la Audiencia de Quito- otorgaron a esta migración una masa ingente de naturales.

Así, en tanto que una de las herramientas de movilización indígena más importantes, la mita se transformó en el mecanismo por el cual los «yndios» llegaban a la ciudad de Quito. Sin embargo, el retorno de estos mitayos a sus lugares de origen no fue tan habitual. ${ }^{72}$ Incluso en la mita minera — bien conocida por sus penurias $-{ }^{73}$ se produjo la misma paradoja. Como ha observado Gil Montero, los naturales que servían la mita en Potosí terminaban, en muchos casos, convirtiéndose en residentes permanentes como trabajadores libres en el centro urbano minero al que habían acudido como mitayos. Así, de la misma manera que tratar de «eludir la mita no significaba necesariamente que huyeran del trabajo minero», ${ }^{74}$ evitar el trabajo como mitayos en los obrajes no significaba huir de aquellos espacios donde esta manufactura se estaba extendiendo.

La ciudad de Quito, donde la extensión de los obrajuelos permitió dar cabida a un amplio número de trabajadores libres, se convirtió en un foco de especial atracción. De ahí que la mita se convirtiera en un motor de movilización poblacional no tanto por la huida de la misma, sino a partir de la transformación de los mitayos en residentes permanentes de la ciudad. De la misma manera que involuntariamente la mita propició la aparición de forasteros ${ }^{75}$ indirectamente se convirtió en herramienta a través de la cual los indígenas llegaban a la ciudad de Quito. Se entiende así el mantenimiento de un flujo migratorio masivo y constante que fue capaz de sustentar el tamaño poblacional de la ciudad de Quito hasta finales del siglo XVII.

70 Cook hace la misma apreciación para la inesperada aparición del indígena forastero como una nueva clase de natural a consecuencia de la legislación del virrey Francisco de Toledo. Ibidem, 145.

71 Situación que había ocurrido también con los repartimientos en Ciudad de México. Jalpa Flores, 2010, 89.

72 Esta realidad ya la señalaba el padre Bernabé Cobo para el caso de Lima, donde «demás de estos indios de mita o repartición, son muchos los que voluntariamente se vienen a alquilar de sus tierras; los cuales suelen ganar uno y dos reales más cada día que los primeros, y de estos acostumbran muchos, después de haber cumplido con su obligación y mita, quedarse por algún tiempo a ganar jornal». Cobo, 1964 [1653], II, 319.

73 Konetzke, 1971, 184-186.

74 Gil Montero, 2013, 58.

75 No sería esta la única consecuencia inesperada de los cambios en el servicio de la mita. Cook $(1989,145)$ lleva a cabo apreciaciones similares al constatar la inesperada aparición del indígena forastero como una nueva clase de natural, a consecuencia de la legislación del virrey Francisco de Toledo. 


\section{Hacia la urbe, una realidad compleja}

Al buscar un único elemento explicativo de la acción social —en este caso de la emigración de indígenas hacia la ciudad de Quito - se corre el riesgo de simplificar en demasía. Los hechos humanos presentes y pretéritos, muy raramente pueden ser explicados a partir de un único motor, de una única causa o de un único elemento. Así, a los principales factores económicos ya señalados previamente, los análisis históricos añaden otro tipo de elementos — culturales, sociales, etc.— que si bien marcaron decisivamente los contextos urbanos han sido considerados en ocasiones causas secundarias de la migración hacia los espacios urbanos. ${ }^{76}$

Para la ciudad de Quito en el siglo XVII, fue la conjunción de numerosos elementos la que permitió desarrollar un contexto de atracción poblacional que perduró aproximadamente siglo y medio. De esta manera, se trataba de una movilización indígena determinada no por la huida de un contexto rural, sino más bien por la atracción que podía llegar a desarrollar un centro urbano. A este respecto, amplios hubieron de ser los beneficios y ventajas que la urbe otorgaba para que los mitayos, a pesar de las problemáticas señaladas — mortandad, tributación forastera y vagabunda- y de aquellas asociadas a la propia migración, decidiesen permanecer en la ciudad de Quito.

Desde mediados del siglo XVI, el cobro del tributo en especie fue sustituido paulatinamente por su valor en metálico. ${ }^{77}$ Aunque las repercusiones de este hecho sobre el mundo indígena están todavía por analizar con precisión, ${ }^{78}$ el contexto que esta transformación iba configurando determinó su decisiva influencia sobre las migraciones indígenas hacia el ámbito urbano. Al fin y al cabo, la administración hispana demandaba a los «yndios» el pago del tributo en moneda. ${ }^{79}$ Sin embargo, a la falta de actividad minera

76 Jalpa Flores, 2010, 82.

77 Aunque este cambio no se circunscribe al caso quiteño sino que ocurrió en gran parte del virreinato, quizás la evidencia más clara de esta modificación sea que, para la ciudad de Quito en el siglo XVII, incluso al señalar dentro de los tributos una o media ave se hacía su equivalencia monetaria exacta, probablemente esperando que los naturales no entregasen miles de aves a las Cajas Reales en cada tercio.

78 Caillavet, 2000, 253.

79 Incluso las aves con las que se pagaba parte del tributo y que aparecen en las cartas cuentas tienen un valor monetario fijado, un real. Es probable que dichos tributos no se pagaran en especie, sino que se pagase el dicho un real. De haber sido un pago «en aves» dicha carta cuenta debería ser mucho más específica en torno al tipo y edad del propio animal. Valga como ejemplo el libro VIII de la obra de Bernabé Cobo, dedicado enteramente a las aves que se encontraron en el Nuevo Mundo. Cobo, 1964 [1653], I, 313-331. 
en la Audiencia de Quito se unía el interés por mantener en los escalafones sociales más altos la moneda existente,${ }^{80}$ por lo que esta no era de fácil obtención.

Si bien se implementaron determinadas estrategias - como el traspaso de la obligación monetaria de la comunidad al obraje de comunidad,$-{ }^{81}$ lo cierto es que en gran medida los indígenas desarrollaban sus vidas alejados de este numerario, comprando a partir de censos — prueba de una sociedad descapitalizada_,${ }^{82}$ o intercambiando mediante el trueque. ${ }^{83} \mathrm{Y}$ sin embargo, de una manera u otra los naturales debían hacer frente, tanto en el ámbito urbano como en el rural, a un tributo exigido en moneda.

En un territorio sin grandes centros mineros como la Audiencia de Quito, su capital en tanto que sede de las cajas reales, se configuró como el espacio predilecto para que los indígenas consiguieran numerario por varias razones. La primera, la variada oferta laboral. Aunque, como en otras urbes, los naturales quiteños se dedicaron a actividades poco remuneradas, la masiva migración y el auge económico les permitió acceder, aunque de forma diversa, a gran parte de los sectores productivos de la ciudad. ${ }^{84} \mathrm{La}$ segunda, la existencia de salarios más elevados. ${ }^{85} \mathrm{Si}$ la variada oferta laboral concedía mayores posibilidades por el simple hecho de ampliar la gama de opciones, ${ }^{86}$ la existencia de salarios más elevados, incluso en actividades que también se desarrollaban en el espacio rural, otorgaba una ventaja sustancial a los indígenas.

Así, en sectores como el textil, donde los naturales contaban con una amplia tradición y una reciente experiencia en los obrajes rurales, su migración a la ciudad o su permanencia tras el servicio mitayo los convertía en trabajadores cualificados. Si el salario como indios mitayos en los obrajes del espacio rural se situaba entre 20 y 24 pesos anuales, ${ }^{87}$ ascendiendo a

80 Tyrer, 1988, 89. La misma escasez de moneda sellada en las transacciones diarias es mencionada para Bolivia por Escobari de Querejazu, 2005, 223.

81 Planteamiento similar defendía Soasti Toscano, 2001, 41.

82 Mena García, 1996, 5.

83 Un trueque que se desarrollaba en una economía monetaria por lo que, como evidenciaban las tasaciones tributarias —en las que un ave equivalía a medio real—, se calculaba el valor de los productos en moneda.

84 A diferencia de otros lugares donde parecen haber sido meros servidores domésticos. Barrios Escobar, 1996, 137.

85 Esta hipótesis la planteó para el caso limeño Charney, 1996, 14.

86 Como señala Vergara Ormeño $(1997,139)$, esta posibilidad se daba, pero las causas que movilizaban a los indígenas eran más complejas.

87 Se entiende que un año laboral tendría unos 312 días, como señala Phelan, 1996, 123. 
entre 35 y 40 pesos a comienzos del siglo XVII ${ }^{88}$ las pagas que percibían en los obrajes privados de la urbe se duplicaban. ${ }^{89}$ De esta manera, el importante crecimiento de la manufactura obrajera en la Audiencia, caracterizado en la ciudad de Quito y sus contornos por los «obrajuelos», trapiches y batanes privados, ${ }^{90} \mathrm{se}$ convirtió en uno de los alicientes principales de la migración indígena a la ciudad.

A fin de cuentas, si al hablar de la economía colonial Assadourian señalaba que «la constante es reducir al mínimo indispensable el tiempo de trabajo necesario que el indígena dedica a la creación de sus necesidades básicas y elevar al máximo el tiempo de trabajo excedente destinado al sector exportador» $;{ }^{91}$ al analizar esta misma realidad social desde el punto de vista de los indígenas, el planteamiento lógico es el opuesto. Estos naturales, obligados a pagar un tributo en moneda iban a buscar dedicar el mínimo tiempo posible a obtener los recursos para pagarlo.

Resulta paradójico observar cómo la manufactura obrajera quiteña, cuyo origen había sido otorgar medios a las comunidades para hacer frente a los tributos ${ }^{92}$ y evitar así la migración de los naturales fuera de sus comunidades, terminó impulsando el fenómeno que trataba de combatir. En definitiva, la convivencia en la urbe de mitayos — con salarios más bajos- $-\mathrm{y}$ trabajadores libres - mejor remunerados- hubo de ser un factor de permanencia sumamente poderoso. En todo caso, no se puede achacar a la manufactura textil un papel exclusivo. Este fenómeno de diferenciación salarial se produjo en otros sectores laborales como la construcción, en donde esta convivencia también llevó a los indígenas a tratar de permanecer en la capital como trabajadores libres una vez terminado el servicio de la mita. Así, que los «yndios» se convirtieran en mano de obra mayoritaria en todos los escalafones del sector de la construcción en pleno auge arquitectónico

88 Larraín Barros, 1980, 123. Si bien las opiniones varían y según Rueda Novoa (1988, 85) hasta 1680 se mantuvo en 24 patacones (o pesos) de a ocho reales, las ordenanzas de Matías de Peralta reglamentan un salario único para los trabajadores en 18 pesos anuales, con la salvedad de turdidores y cardadores. Moreno Yánez, 1981b, 283.

89 Powers, 1994, 164.

90 Ponce Leiva, 1998, 396.

91 Assadourian, 1983, 139.

92 Como ya señalaba Alonso de la Peña Montenegro, haciendo al mismo tiempo referencia a esa doble vertiente de la manufactura textil, «los indios que trabajan en los obrajes son en dos maneras: unos que trabajan en obrajes de comunidad, y estos están repartidos por la justicia para que sirvan en ese ministerio, para que con lo que se devenga de su trabajo se paguen los tributos de aquellos pueblos de donde son vecinos. Otros son indios voluntarios que traban obrajes de particulares y todo lo que gana por su trabajo es suyo y pueden disponer de ello a su voluntad». Peña Montenegro, 1995 [1668], 647. 
y artístico quiteño, evidencia la capacidad que tuvieron estos naturales para expandirse y desarrollarse laboralmente en la urbe. ${ }^{93}$

En todo caso, las realidades sociales son múltiples y sumamente complejas. Si bien se defiende aquí la concatenación de causas y efectos como configuradores de varios factores principales de atracción — mita, tributo, mejores oportunidades laborales y mejores salarios- no son en ningún caso suficientes para explicar un fenómeno de la magnitud de la movilidad indígena hacia la ciudad de Quito. Al fin y al cabo, la capital de la Audiencia era un complejo entramado social y económico cuyos múltiples componentes constitutivos pudieron sumarse a la necesidad de erario para convertirse en un poderoso factor de atracción.

De seguro cuestiones como una tradición prehispánica muy propensa a las movilizaciones entre los diferentes nichos, el control de determinados sectores laborales desde tiempos prehispánicos, la importancia del textil para los «yndios» quiteños, la necesidad de acudir ante los jueces y fiscales de la capital, el papel de escribanos y otros oficiales de la administración, los «servicios» que aparecían en la ciudad o el simple paso de una comitiva administrativa se sumaron a los elementos causantes de una movilización y migración indígena de gran calado y profundas consecuencias.

\section{Conclusiones}

Para algunos análisis el factor económico, principalmente la evasión del tributo y del servicio de la mita, habían sido las razones principales que llevaron a los «yndios» hacia las ciudades. ${ }^{94}$ Se argumentaba que la Monarquía hispánica había «reducido» a las poblaciones indígenas, concentrándolas y numerándolas en función de su residencia estable, con el interés de controlarlas, hacerlas servir la mita y pagar el tributo. En consecuencia, en el momento en el que estas poblaciones migraban hacia las urbes, las dinámicas que ponían en funcionamiento facilitaban la evasión de sus «obligaciones» fiscales y del «servicio mitayo».

Sin embargo, desde al menos principios del siglo XVII, se desarrollaron en la ciudad de Quito numerosas formas de tributación urbanas. Así, no solo los naturales que pagaban en sus comunidades rurales y que se habían

93 Webster, 2012, 16.

94 Varios ejemplos de estas hipótesis para diversas ciudades: Minchom, 2007, 80. Jalpa Flores, 2010, 82. Barrios Escobar, 1996, 158. 
ido a la ciudad, sino también la amplia masa de forasteros y «vagamundos» residentes en Quito, encontraron en la capital de la Audiencia un espacio donde a través de viejas y nuevas parcialidades seguían tributando. En definitiva, una parte importante de los «yndios» que habitaron Quito en el siglo XVII, no solo tributaba sino que sus cargas fiscales eran igual de onerosas que en el ámbito rural.

Al mismo tiempo, el espacio urbano no se convirtió en un lugar exento de trabajos mitayos, sino todo lo contrario. La ciudad de Quito contó con una amplia gama de sectores laborales — construcción, textil, reparación de acequias, abastecimiento de agua, etc.- - susceptibles de ser beneficiados con mano de obra mitaya. Así, de la misma manera que la mita minera de Potosí no se transformó en factor de movilización por la huida de la misma, sino por la conversión de indígenas mitayos en residentes de la ciudad; la mita de plaza quiteña y, sobre todo, la desarrollada en las manufacturas textiles de la ciudad, se convirtieron en los grandes mecanismos involuntarios de migración indígena permanente a la urbe. Los naturales, «arrastrados» hacia la capital por este trabajo forzado, siguieron residiendo en ella una vez finalizado el servicio, pasando de migrantes temporales a residentes.

La causa de esta transformación, en otras palabras, los elementos que configuraron la atracción que la ciudad de Quito suscitaba entre los indígenas, iban mucho más allá de la difícil evasión tributaria y la escasa huida de la mita, ambos procesos factibles tanto en la ciudad como en el campo. Los «yndios», conscientes de las problemáticas a las que las nuevas realidades del siglo XVII les hacían enfrentarse, encontraron en el espacio urbano un lugar donde desarrollar nuevas estrategias, un ámbito donde acceder a nuevos estratos sociales y donde responder a los requerimientos económicos coloniales. Su migración fue más allá del mero traslado geográfico, convirtiéndose - por el papel activo de los indígenas - en una adaptación que, junto a otras muchas que hubieron de implementar estos naturales ${ }^{95}$ transformó sus prácticas cotidianas y convirtió la ciudad de Quito, de forma palpable, en una urbe de «españoles e indios». ${ }^{96}$

Recibido el 20 de octubre de 2017 Segunda versión el 10 de marzo de 2018 Aceptado el 17 de abril de 2018

95 Ciriza-Mendívil, 2017b.

96 Haciendo referencia a la descripción hecha en 1631 por el presidente de la Audiencia de Quito, Antonio Morga. En Ponce Leiva, 1992, 130. 


\section{Referencias bibliográficas}

Alchon, Suzanne A., Native Society and Disease in Colonial Ecuador, Cambridge, Cambridge University Press, 1991.

Ares Queija, Berta, «Mestizos en hábito de indios: ¿estrategias transgresoras o identidades difusas?», en Loureiro, R. M. y Gruzinski, S. (coords.), Passar as fronteiras. Actas do II Colóquio Internacional sobre Mediadores Culturais, séculos XV a XVIII, Lagos, Centro de Estudos Gil Eanes, 1999, 133-146.

Argouse, Aude, « ¿Son todos caciques? Curacas, principales e indios urbanos en Cajamarca (siglo XVII)», Bulletin de l'Institut Français d'Études Andines, 37, 1, Lima, 2008, 163-184.

Assadourian, Carlos Sempat, El sistema de la economía colonial. El mercado interior, regiones y espacio económico, México, Nueva Imagen, 1983.

Ayala Mora, Enrique (ed.), Nueva Historia del Ecuador. Vol. 3 Época Colonial I. Conquista y Primera Etapa Colonial, Quito, Corporación Editora Nacional, 1983.

Barrios Escobar, Lina E., La alcaldía indígena en Guatemala: época colonial (1500-1821), Guatemala, Universidad Rafael Landívar, 1996.

Bonnett, Diana, El Protector de Naturales en la Audiencia de Quito, siglos XVII y XVIII, Quito, FLACSO Ecuador, 1992.

Burgos Guevara, Hugo, Primeras Doctrinas en la Real Audiencia de Quito 15701640. Estudio preliminar y transcripción de las relaciones eclesiales y misionales de los siglos XVI y XVII, Quito, Abya-Yala, 1995.

Caillavet, Chantal, Etnias del Norte: Etnohistoria e historia de Ecuador, Quito, Abya-Yala / IFEA, 2000.

Castro Gutiérrez, Felipe (coord.), Los indios y las ciudades de Nueva España, México, UNAM, 2010a.

Castro Gutiérrez, Felipe, «Los indios y la ciudad. Panorama y perspectivas de investigación», en Castro Gutiérrez, F. (coord.), Los indios y las ciudades de Nueva España, México, UNAM, 2010b, 9-34.

Charney, Paul, «El indio urbano: un análisis económico y social de la población india de Lima en 1613», Histórica, XII, 1, Lima, 1988, 5-33.

Charney, Paul, «Negotiating Roots: Indian Migrants in the Lima Valley During the Colonial Period», Colonial Latin American Historical Review, 5, 1, Albuquerque, 1996, 1-20.

Charney, Paul, «"Much Too Worthy...": Indians in Seventeenth-Century Lima», en Velasco Murillo, D.; Lentz, M. y Ochoa, M. R. (eds.), City Indians in Spain's American Empire: Urban Indigenous Society in Colonial Mesoamerica and Andean South America, 1530-1810, Brighton, Sussex Academic Press, 2012, 87-103.

Ciriza-Mendívil, Carlos D., «Los indígenas quiteños a través de sus testamentos: dinámicas socioculturales en el siglo XVII», Procesos, 45, Quito, 2017a, 9-34. 
Ciriza-Mendívil, Carlos D., «"Por decir ser yndia”. Las difusas fronteras del mestizaje en la ciudad de Quito (siglo XVII)», Colonial Latin American Review, 26, 4, Filadelfia, 2017b, 509-527.

Cobo, Bernabé, Historia del Nuevo Mundo, Madrid, Atlas, 1964 [1653].

Cole, Jeffrey A., The Potosí Mita, 1573-1700: Compulsory Indian Labor in the Andes, Standford, Standford University Press, 1985.

Contreras, Hugo, «Los conquistadores y la construcción de la imagen del "indio" en Chile central», en Araya, A. y Valenzuela, J. (eds.), América colonial: Denominaciones, clasificaciones e identidades, Santiago de Chile, RIL editores, 2010, 48-79.

Cook, Noble David, «Patrones de migración indígena en el Virreinato del Perú: mitayos, mingas y forasteros», Histórica, XIII, 2, Lima, 1989, 125-152.

Escobari de Querejazu, Laura, Caciques, yanacones y extravagantes. La Sociedad Colonial en Charcas s. XVI-XVIII, La Paz, IFEA, 2005.

Espinoza Soriano, Waldemar, Etnohistoria Ecuatoriana. Estudios y documentos, Quito, Abya-Yala, 1999.

Gil Montero, Raquel, «Migración y tributación en los Andes: Chichas y Lípez a fines del siglo XVII», Anuario de Estudios Americanos, 70, 1, Sevilla, 2013, 39-65.

Gil Montero, Raquel, «El tributo andino reinterpretado: El caso del corregimiento de Lípez», European Review of Latin American and Caribbean Studies, 99, Ámsterdam, 2015, 69-98.

Glave, Luis Miguel, «Mujer indígena, trabajo doméstico y cambio social en el virreinato peruano del siglo XVII: La ciudad de La Paz y el Sur Andino en 1684», Bulletin de l'Institut Français d'Études Andines, XVI, 3-4, Lima, 1987, 39-69.

Gómez García, Lidia E., «Las fiscalías en la Ciudad de los Ángeles, siglo XVII», en Castro Gutiérrez, F. (coord.), Los indios y las ciudades de Nueva España, México, UNAM, 2010, 173-195.

Gómez Gómez, Mauricio Alejandro, Del chontal al ladino. Hispanización de los indios de Antioquia según la visita de Francisco de Herrera Campuzano, 1614-1616, Medellín, Universidad de Antioquia, 2015.

Jalpa Flores, Tomás, «Migrantes y extravagantes. Indios de la periferia en la ciudad de México durante los siglos XVI-XVII», en Castro Gutiérrez, F. (coord.), Los indios y las ciudades de Nueva España, México, UNAM, 2010, 79-104.

Jara Chávez, Hólguer, «Quito antes de San Francisco de Quito», en Quito Prehispánico, Quito, Museo Archivo de Arquitectura del Ecuador, 2008, 81-114.

Konetzke, Richard, América Latina. II. La época colonial, Madrid, Siglo XXI, 1971.

Landázuri N., Cristóbal (comp.), Visita y numeración de los pueblos del Valle de los Chillos, 1551-1559, Quito, Marka / Abya-Yala, 1990.

Larraín Barros, Horacio, Cronistas de raigambre indígena, Otavalo, Instituto Otavaleño de Antropología, 1980. 
Matienzo, Juan de, Gobierno del Perú (1567), edición y estudio preliminar por G. Lohmann Villena, París-Lima, Instituto Francés de Estudios Andinos, 1967.

Mena García, María del Carmen, «Censos eclesiásticos y propiedad urbana: una relación conflictiva», Caravelle, 66, Toulouse, 1996, 5-26.

Minchom, Martin, El pueblo de Quito, 1690-1810: demografía sociorracial y protesta popular, Quito, FONSAL, 2007.

Moreno Yánez, Segundo E., Pichincha. Monografía histórica de la región nuclear ecuatoriana, Quito, Consejo Provincial de Pichincha, 1981a.

Moreno Yánez, Segundo E., «El "Formulario de las Ordenanzas de indios”: una regulación de las relaciones laborales en las haciendas y obrajes del Quito colonial y republicano», en Moreno Y., S. y Oberem, U., Contribución a la etnohistoria ecuatoriana, Quito, Instituto Otavaleño de Antropología, 1981b, 277-297.

Moreno Yánez, Segundo E., «Don Leandro Sepla y Oro, un cacique andino de finales de la colonia: estudio biográfico», en Moreno Yánez, S. y Thyssen, S. (comps.), Antropología del Ecuador. Memorias del Primer Simposio Europeo sobre Antropología del Ecuador, Quito, Abya-Yala, 1989, 245-266.

Ortiz de la Tabla Ducasse, Javier, Los encomenderos de Quito 1534-1660. Origen y evolución de una élite colonial, Sevilla, CSIC, 1993.

Paredes Martínez, Carlos, «Convivencia y conflictos: la ciudad de Valladolid y sus barrios de indios, 1541-1809», en Castro Gutiérrez, F. (coord.), Los indios y las ciudades de Nueva España, México, UNAM, 2010, 35-56.

Peña Montenegro, Alonso de la, Itinerario para párrocos de indios, Madrid, CSIC, 1995 [1668].

Pérez Tamayo, Aquiles R., Las Mitas en la Real Audiencia de Quito, Guayaquil, Universidad de Guayaquil, 1987 [1947].

Phelan, John Leddy, El Reino de Quito en el siglo XVII. La política burocrática en el Imperio Español, Quito, BCE, 1996 [1967].

Poloni-Simard, Jacques, «Historia de los indios en los Andes, los indígenas en la historiografía andina: análisis y propuestas», Anuario del Instituto de Estudios Histórico-Sociales, 15, Buenos Aires, 2000, 87-100.

Poloni-Simard, Jacques, El mosaico indígena. Movilidad, estratificación social y mestizaje en el corregimiento de Cuenca (Ecuador) del siglo XVI al XVIII, Quito, Abya-Yala / IFEA, 2006.

Ponce Leiva, Pilar (ed.), Relaciones Histórico-Geográficas de la Audiencia de Quito, siglos XVI-XIX, Madrid, CSIC, 1992, t. II.

Ponce Leiva, Pilar, Certezas ante la incertidumbre. Élite y Cabildo de Quito en el siglo XVII, Quito, Abya-Yala, 1998.

Ponce Leiva, Pilar y Amadori, Arrigo, «Redes sociales y ejercicio del poder en la América Hispana: consideraciones teóricas y propuestas de análisis», Revista Complutense de Historia de América, 34, Madrid, 2008, 15-42.

Powers, Karen V., Prendas con pies. Migraciones indígenas y supervivencia cultural en la Audiencia de Quito, Quito, Abya-Yala, 1994. 
Ramón Valarezo, Galo, «Quito aborigen: Un balance de sus interpretaciones», en Enfoques y estudios históricos. Quito a través de la Historia, Quito, Municipio de Quito / Junta de Andalucía, 1992, 29-64.

Ramos, Gabriela, Muerte y conversión en los Andes: Lima y Cuzco, 1532-1670, Lima, IFEA, 2010.

Ramos, Gabriela, «"Mi tierra": Indigenous Migrants and their Hometowns in the Colonial Andes», en Velasco Murillo, D.; Lentz, M. y Ochoa, M. (eds.), City Indians in Spain's American Empire. Urban Indigenous Society in colonial Mesoamerica and Andean South America, 1530-1810, Brighton, Sussex Academic Press, 2012, 128-147.

Rebolledo González, Loreto, Comunidad y Resistencia. El caso de Lumbisí en la colonia, Quito, FLACSO / Abya-Yala, 1992.

Rueda Novoa, Rocío, El Obraje de San Joseph de Peguchi, Quito, Abya-Yala, 1988.

Saignes, Thierry, Caciques, Tribute and Migration in the Southern Andes: Indian Society and the 17th Century Colonial Order (Audiencia de Charcas), Londres, University of London, 1985.

Salomon, Frank, «Seis comunidades indígenas en las cercanías de Quito, 1599: La visita de Gaspar de San Martín y Juan Mosquera», Boletín de la Academia Nacional de Historia de Ecuador, XIL, 127, Quito, 1976, 139-190.

Salomon, Frank, Los señores étnicos de Quito en la época de los incas. La economía política de los señores norandinos, Quito, Instituto Metropolitano de Patrimonio, 2011 [1986].

Sánchez Albornoz, Nicolás, «Migración urbana y trabajo. Los indios de Arequipa, 1571-1645», en Bagú, S. et al., De historia e historiadores. Homenaje a José Luis Romero, México, Siglo Veintiuno, 1982, 259-281.

Sánchez Albornoz, Nicolás, «La mita de Lima. Magnitud y procedencia», Histórica, XII, 2, Lima, 1988, 193-210.

Sánchez Albornoz, Nicolás, La ciudad de Arequipa, 1573-1645. Condición, migración y trabajo indígenas, Arequipa, Universidad Nacional de San Agustín, 2003.

Soasti Toscano, Guadalupe, «Mitayos, tributarios y mercaderes», en Porras, M. E. y Calvo-Sotelo, P. (coords.), Ecuador-España. Historia y Perspectiva. Estudios, Quito, Embajada de España en el Ecuador / Archivo Histórico del Ministerio de Relaciones Exteriores del Ecuador, 2001, 40-43.

TePaske, John J. y Klein, Herbert S., The Royal Treasuries of the Spanish Empire in America, Durhan, Duke University Press, 1982, 4 vols.

Tyrer, Robson Brines, Historia Demográfica y Económica de la Audiencia de Quito: población indígena e industria textil 1600-1800, Quito, BCE, 1988.

Valenzuela Márquez, Jaime, «Indios urbanos: inmigraciones, alteridad y ladinización en Santiago de Chile (siglos XVI-XVII)», Historia Crítica, 53, Bogotá, 2014, 13-34. 
Vergara Ormeño, Teresa, «Migración y trabajo femenino a principios del siglo XVII: el caso de las indias en Lima», Histórica, XXI, 1, Lima, 1997, 135-157.

Webster, Susan V., Quito, ciudad de maestros: Arquitectos, edificios y urbanismo en el largo siglo XVII, Quito, Abya-Yala, 2012.

Zambrano Escovar, Marta, Trabajadores, villanos y amantes: encuentros entre indígenas y españoles en la ciudad letrada. Santa Fe de Bogotá (1550-1650), Bogotá, Instituto Colombiano de Antropología e Historia, 2008.

Zulawski, Ann, «Forasteros y yanaconas: la mano de obra de un centro minero en el siglo XVII», en Harris, O.; Larson, B. y Tandeter, E. (comps.), La participación indígena en los mercados surandinos. Estrategias y reproducción social. Siglos XVI a XX, La Paz, CERES, 1987, 159-192. 